\title{
Controlling Coagulation Process: From Zeta Potential to Streaming Potential
}

\author{
Djamel Ghernaout ${ }^{1,2, \text { * }}$, Abdulaziz Ibraheem Al-Ghonamy ${ }^{2}$, Mohamed Wahib Naceur ${ }^{1}$, \\ Ahmed Boucherit $^{1}$, Noureddine Ait Messaoudene ${ }^{2}$, Mohamed Aichouni ${ }^{2}$, \\ Ammar Abdallah Mahjoubi ${ }^{2}$, Noureddine Ali Elboughdiri ${ }^{2}$ \\ ${ }^{1}$ Department of Chemical Engineering, University of Blida, Blida, Algeria \\ ${ }^{2}$ Binladin Research Chair on Quality and Productivity Improvement in the Construction Industry, College of Engineering, University of Ha'il, \\ Ha'il, Saudi Arabia
}

\section{Email address:}

dj.ghernaout@uoh.edu.sa (D.Ghernaout),djamel_andalus@hotmail.com (D.Ghernaout)

\section{To cite this article:}

Djamel Ghernaout, Abdulaziz Ibraheem Al-Ghonamy, Mohamed Wahib Naceur, Ahmed Boucherit, Noureddine Ait Messaoudene, Mohamed Aichouni, Ammar Abdallah Mahjoubi, Noureddine Ali Elboughdiri. Controlling Coagulation Process: From Zeta Potential to Streaming Potential. American Journal of Environmental Protection. Special Issue: Cleaner and Sustainable Production.

Vol. 4, No. 5-1, 2015, pp. 16-27. doi: 10.11648/j.ajeps.s.2015040501.12

\begin{abstract}
This review concerns the using of Zeta and streaming potentials in the coagulation process control. Coagulation process is usually explained by charge neutralization mechanism. The negative charge may be quantified by Zeta potential or streaming potential measures. Prior to the advent of streaming current monitors, Zeta meters were the primary instruments for measuring electrokinetic properties as related to coagulant dose. Both instruments measure the potential and indirectly the particle surface charge, but use very different methods. Even if the on-line streaming current monitor can provide coagulation process optimization when properly installed, maintained, and interpreted, jar tests experiments and Zeta meters remain indispensable.
\end{abstract}

Keywords: Electrophoretic Mobility, Zeta Potential, Streaming Potential, Streaming Current, Streaming Current Detector, Coagulation Control

\section{Introduction}

Conventional water technology implies the treatment of extremely complex colloidal dispersions through coagulation/flocculation process [1]. Coagulating such colloids is achieved through controlling their surface electrical charges. This action is realized by adsorption of ions of opposite charge to the colloid surface [2,3]. This adsorption decreases the mutual electrostatic repulsion between dispersed colloids that prevents their aggregation into flocs [4-6].

This mechanism is called charge neutralization control [710]. Controlling the resultant electric charge of the colloid is the main key to the successful steps implicated in aggregation of colloids in raw waters [5,11]. In 1966, the streaming current detector was invented [12]. Prior to this device, there was no on-line, efficient tool to control a characteristic proportional to the value of charge neutralization other than to control its result (in other words, coagulation as studied in simple jar tests) $[5,13,14]$.

In this review paper, we discuss the evolution from Zeta potential to streaming potential as a mean for coagulant control. As these parameters are related to the colloid charge, we also briefly discuss the mechanism of charge neutralization.

\section{From Zeta Potential to Streaming Potential}

For over 30 years, with a large success streaming current monitors have been used for on-line coagulant and polymer control in water and wastewater plants [15]. Before 25 years, users have not at their possession an appropriate mean to check-up the on-line unit operation and/or response to process variations. As with any control device, when the reading or output varies, users have to know if it is due to a process variation, or if something is not correct with the 
control device. Moreover, if the technician makes a chemical pump adjustment and the on-line streaming current device doesn't respond correctly, there may be issues with the pump, an empty feed tank, etc., and nothing bad with the device. Users have to know something is not correct and have quick troubleshooting methods. The laboratory streaming current monitor gives them that mean. The laboratory unit is also a great tool for users to see how changes such as $\mathrm{pH}$, alkalinity, turbidity, mixing time, and chemical dosages affect the streaming current reading [15].

On the other hand, jar tests have been largely used to determine the coagulant dose. Jar tests have disadvantages in that they are time consuming, intermittent, and are subject to variations in user's visual observations [15]. To ameliorate coagulant demand determinations, Zeta meters have been used to increase jar tests results quality [16]. Zeta potential is an indirect evaluation of particle surface charge [16]. Before the use of streaming current monitors, Zeta meters were the first instruments for evaluating electrokinetic properties as related to coagulant dose [17]. Both tools measure charge, but use different mechanisms [15].

The Zeta meter (Fig. 1(a)) uses a stereoscopic microscope to control particle motion through a glass cell named an electrophoresis cell. Electrodes in each end of the cell create an electric field. Colloids having a positive charge $(+)$ will move toward the anode (-), and negative colloids (-) toward the cathode $(+)$. Colloid velocity and direction both of them are related to its Zeta potential. The Zeta potential relating to right coagulant dose changes from water to water. It is crucial to keep in mind that a Zeta potential of zero is difficult even if the optimum dose is fixed. The aim is to decrease repulsive forces until particle collisions cause agglomeration, and reach the correct particle size/density conducting to the best flocculation, settling, and filtration. In fact, this "correct charge" value may be negative, zero, or positive, but frequently negative. Zeta potential is usually expressed in $\mathrm{mV}$. An usual correct potential (and consequently the electric charge) might be in the range -10 to $-5 \mathrm{mV}$ [15].
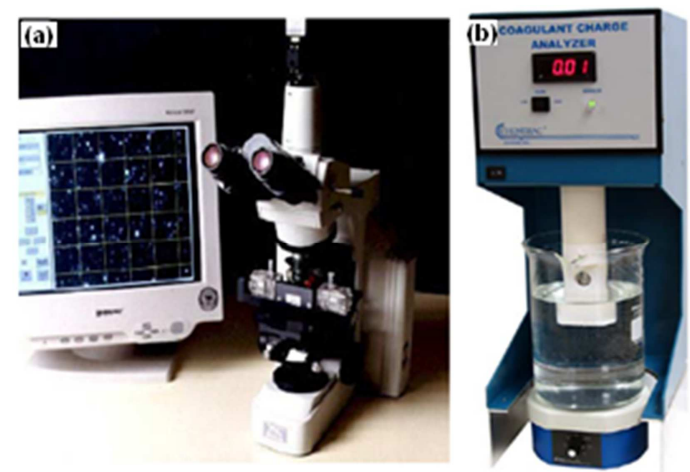

Fig. 1. Zeta meter (a) and (b) streaming current monitor [15].

In fact, the streaming current monitor (Fig. 1(b)) is a charge evaluating instrument. The charge evaluated is the net ionic and colloid surface charge (positive and negative) in the sample being examined. However, streaming current is in relation to Zeta potential by:

$$
S C \alpha \frac{Z P \times D}{N}
$$

Where $S C$ is the streaming current, $Z P$ is the Zeta potential, $D=$ dielectric constant, and $N=$ viscosity of the fluid. The treated sample flows into the chamber where it is drawn into the bore during the piston upstroke and is expelled on the downstroke. Colloids in the sample are temporarily fixed on the piston and cylinder surfaces [5]. As the water is moved back and forth, mobile counter-ions surrounding these particles are moved downstream to the electrodes. This reciprocating motion of like charges causes an alternating current to be created which is known as streaming current. This current is amplified, through the convenient electronics, and read as the streaming current value [15].

In fact, streaming current is another mean to evaluate Zeta potential. However, the measured numerical values are not identical. For example, a Zeta potential of $-10 \mathrm{mV}$ is not -10 streaming current units. This is not a problem in practical use due to the fact that the optimum treatment program is always empirically determined for each plant. When it is question to remove turbidity, the aim is to reach optimum particle size/density. When it is question to remove organics, as this the case of enhanced coagulation, optimum dosage may not even be in relation with particle collisions and floc birth [18]. This constitutes a real advantage over Zeta meters, which rely on visual observation of colloids [15].

Moreover, optimum coagulation chemistry is generally known as "the lowest dosage of all chemicals that results in the desired removal of contaminants with the lowest total operating costs." The on-line streaming current monitor can assure this optimization when conveniently installed, maintained, and interpreted [15].

In their study, Wäsche et al. [19] compared Zeta potential, as evaluated with the electrokinetic sonic amplitude method, to streaming potential as evaluated with the particle charge detection method. The measurements have been realized on identical suspensions of $\alpha-\mathrm{Al}_{2} \mathrm{O}_{3}, \mathrm{SiC}$ and $\mathrm{Si}_{3} \mathrm{~N}_{4}$ with a solids volume fraction of $1 \%$ and $10 \%$. Zeta potential and streaming potential are related by a linear relation [20]. For this relationship, the correlation coefficients are better than 0.99 for the suspensions with $1 \%$ solids loading. For the suspensions with $10 \%$ solids loading, correlation coefficients are slightly lower due to the influence of increasing viscosity. Regardless of lower correlation at the higher solids loading, the isoelectric $\mathrm{pH}$ is constant within the limits of accuracy of the $\mathrm{pH}$ measurements [19].

A good review on the history of electrokinetic phenomena is presented by Wall [21]. An updated review on the measurement and interpretation of electrokinetic phenomena may be found elsewhere [16].

\section{Colloidal Particles and the Double Layer Model}

\subsection{Colloidal Particles}

Turbidity is constituted by suspended particles in water in 
the size range of approximately 0.01 to $100 \mu \mathrm{m}$ in size [22]. The larger portion can generally be removed by settling. The smaller particles, with sizes of $<5 \mu \mathrm{m}$, are called colloidal particles. Colloids are characterized by slow sedimentation velocities and so cannot be easily removed by settling. The behavior of colloids in suspension is greatly affected by their electrostatic charge [23]. This colloidal charge appears because of the uneven surface characteristics of the colloids and is usually negative. The charge on each colloid will be in repulsion with others and avoid important flocculation from producing. Charge neutralization is the main goal of coagulation $[22,24,25]$.

\subsection{The Double Layer Model}

The double layer model is often called to interpret the distribution of electric charges around each colloid [22,26].

For practical interests we will suppose a negatively charge colloid. Nearest to the negative surface of the colloid there is a layer of strongly fixed positive ions - this is called the Stern layer. Further positive ions are still fixed to the colloid but are repelled by the Stern layer [22]; in the same manner, negative ions are attracted to the positive ions but repelled by the colloid [22]. A dynamic equilibrium of negative and positive charges constitutes, outside the Stern layer, a layer known as the diffuse layer. The presence of positive ions in the diffuse layer proportionally decreases as the distance from the colloid increases until beyond a certain point the ion concentrations are the same as the equilibrium in the water [22].

The strongly fixed positive ions near the surface and the charged layer surrounding this is where the name double layer originates from [26]. The surface and Stern layer together are actually termed a double layer. Moreover, the surface with a diffuse layer constitute a double layer. However, the surface plus a Stern layer plus a diffuse layer constitute a triple layer model.The point just outside the Stern layer is usually known as the shear plane since movement of the colloid through the suspension shears the diffuse layer away [22,23,27-29]. In fact, in some cases, the shear plane can be quite displaced beyond the Stern plane.

The thickness of these layers is a function of the concentration of ions in suspension. At any point from the surface, the charge density is equal to the difference between the concentration of positive and negative ions at that point (Fig. 2) [22,30].

The potential at the separation between the Stern layer and diffuse layer is named the Zeta potential. Evaluating Zeta potential is beneficial as it is a direct determination of the amount of energy required to bring separate particles together [22].

Zeta potential can be evaluated quite easily. This is done by using a microscope to observe turbidity particles inside a thin chamber called an electrophoresis cell. An electric field is applied along the cell, if the particles are negatively charged they will move towards the positive end of the cell, carrying their Stern layer ions with them. The average velocity with which these particles move depends on the Zeta potential value, as it is this that determines the net electrical force operating on the particle and its Stern layer ions [22].

In fact, the relationship between Zeta potential and this average velocity is not always straightforward to calculate, as it is a function of the fluid's viscosity, dielectric constant, conductivity and temperature. Consequently, Zeta potential, which should have units of $\mathrm{mV}$, is often expressed in terms of electrophoretic mobility. This has rather confusing units in velocity per electric field strength, typically $\mu \mathrm{m} / \mathrm{s}$ per $\mathrm{V} / \mathrm{cm}$ [22]. Other disadvantages of measuring Zeta potential in this way include:

- It can only be measured for particles that are large enough to be detected and tracked through a microscope.

- It requires a laboratory technician to operate the apparatus and to observe the particles through a microscope. Consequently, Zeta potential measurement is slow, labor intensive and cannot be performed online.

Zeta potential measurement has useful applications in laboratory studies of coagulation/flocculation processes, but is of little use for online automation [22].

\section{Streaming Potential}

A streaming current and streaming potential are two interrelated electrokinetic phenomena studied in the areas of surface chemistry and electrochemistry (Table 1) [22,31]. They are an electric current or potential which originates when an electrolyte is driven by a pressure gradient through a channel (or capillary) or porous plug with charged walls $[31,32]$. Streaming currents in well-defined geometries are a sensitive method to determine the Zeta potential of surfaces [31].

Table 1. Streaming current and streaming potential [22].

Streaming current and streaming potential

1. A streaming current meter is an instrument for measuring the electric charge that exists on small, suspended particles in liquid. A streaming current meter is the only on-line instrument that can be utilized to evaluate coagulated particle stability for the feedback control of coagulant dosage.

2. The streaming current meter is also referred to as the streaming current detector or streaming potential detector as well as streaming current monitor and streaming current analyzer in various works. The word 'detector' is utilized in earlier literature instead of the words 'meter', 'monitor' or 'analyzer' because earlier streaming current meters were considered to only provide a qualitative indication of the presence and sign of charge, rather than a useful quantitative measurement. The words 1: 'Meter', 2: 'Monitor' and 3: 'Analyzer' all mean the same thing in this context, except that the implication of sophistication increases in this order.

\subsection{Origin of the Streaming Current}

Adjacent to the channel walls, the charge-neutrality of the liquid is violated due to the presence of the electric double layer (Fig. 2) [30] or in other terms the overall free energy is 
equilibrated due to opposing electrical and osmotic pressure forces: a thin layer of counter-ions attracted by the charged surface [31]. The transport of counter-ions along with the pressure-driven fluid flow produces a net charge transport: the streaming current. The reverse effect, creating a fluid flow by applying a potential difference, is named electroosmotic flow [31].

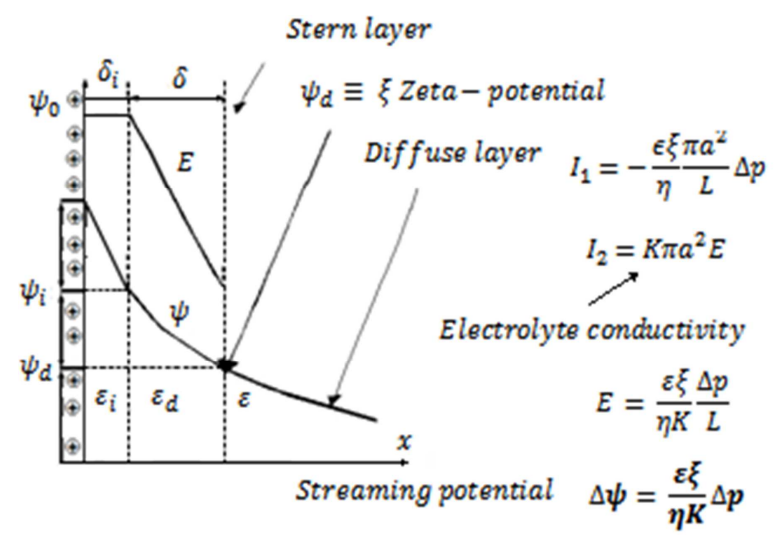

Fig. 2. Electric double layer [30].

\subsection{Measurement Method}

A typical device to determine streaming currents consists of two reversible electrodes placed on either side of a fluidic geometry across which a known pressure difference is applied. When both electrodes are held at the same potential, the streaming current is evaluated directly as the electric current flowing through the electrodes. Alternatively, the electrodes can be left floating, allowing a streaming potential to build up between the two ends of the channel. A streaming potential is defined as positive when the electric potential is higher on the high pressure end of the flow system that on the low pressure end [31].

The value of streaming current observed in a capillary is usually in relation with the Zeta potential through the relation:

$$
I_{s t r}=-\frac{\epsilon_{r s} \epsilon_{0} a^{2}}{\eta} \frac{\Delta P}{L} \zeta
$$

The conduction current, which is equal in magnitude to the streaming current at steady state, is:

$$
I=K_{L} a^{2} \frac{U_{s t r}}{L}
$$

At steady state, the streaming potential built up across the flow system is calculated by:

$$
U_{s t r}=\frac{\epsilon_{r s} \epsilon_{0} \zeta}{\eta K_{L}} \Delta P
$$

Where:

- $I_{s t r}$ : streaming current under short-circuit conditions, A

- $U_{s t r}:$ streaming potential at zero net current conditions, $\mathrm{V}$

- $I_{c}$ : conduction current, A

- $\varepsilon_{r s}$ : relative permittivity of the liquid, dimensionless

- $\varepsilon_{0}$ : electrical permittivity of vacuum, $\mathrm{F} \cdot \mathrm{m}^{-1}$
- $\eta$ : dynamic viscosity of the liquid, $\mathrm{kg} \cdot \mathrm{m}^{-1} \mathrm{~s}^{-1}$

- $\zeta$ : Zeta potential, $\mathrm{V}$

- $\triangle P$ : pressure difference, $\mathrm{Pa}$

- $L$ : capillary length, $\mathrm{m}$

- $a$ : capillary radius, $\mathrm{m}$

- $K_{L}$ : specific conductivity of the bulk liquid, $\mathrm{S} \mathrm{m}^{-1}$.

The above equations assume that:

- the double layer is not too large compared to the pores or capillaries (i.e., $\kappa a>>1$ ), where $\kappa$ is the reciprocal of the Debye length,

- there is no surface conduction (which typically may become important when the Zeta potential is large, e.g., $|\zeta|>50 \mathrm{mV})$,

- there is no electric double layer polarisation [31,33].

\subsection{Streaming Current Isochoric and Non-isochoric. Seismo-Electric Effect}

Streaming potential and streaming current occur in porous bodies when liquid is being pumped through them. These electrokinetic phenomena have been known for almost 200 years [34]. They are largely used for evaluating Zeta potential in porous bodies. The important field of application so far is in the paper industry. Streaming potential is frequently the preferred manner of realizing this measurement. However, the streaming current method does not require conductivity for calculating Zeta potential, which is an advantage. One of the important areas of the streaming current and streaming potential application is seismo-electric effect. This phenomenon is detected in underground rocks when sound waves propagate through. This seismo-electric effect is largely used for characterizing underground formations with regard to water or oil presence [34].

\subsection{The Streaming Current Effect}

The streaming current (or streaming potential) effect is a reverse manifestation of the electrophoresis effect. This occurs when a particle is mechanically moved through the fluid, or the fluid moved past the particle, conducting to a separation of charges pushing a potential to exist [22,35].

A commonly occurring situation is that water with negatively charged particles is forced through a filter. The negatively charged particles become lodged in the filter, while the mobile positively charged ions are swept downstream. This separation of charges produces an electrical potential to exist across the filter, called the streaming potential. If electrodes are inserted upstream and downstream of the filter, then the electrical potential can be determined. The upstream electrode is negative and the downstream electrode is positive [22].

The electrical potential results in a current being conducted upstream through the water to remove the charge separation, this is the streaming current. The electrical potential therefore is a function of the conductivity of the liquid [22].

Streaming current is a more important quantity than streaming potential, as it does not depend on the water's conductivity. Streaming current can be determined whenever 
the water with suspended charged particles is forced through thin capillaries or other barriers to the particle's motion. However, useful determinations are extremely hard to directly make from this effect, since the current generated is extremely small and easily obscured by potentials that exist for other reasons and electrical paths through the environment [22].

\section{Using a Zeta Potential Meter or a Streaming Current Meter}

Zeta potential is a parameter determined in the laboratory; its measurement requires a technician to use a microscope to evaluate it [36]. Provided it these measurements are done correctly, they are very repeatable for different water parameters. Streaming current is an online measurement. A streaming current monitor runs continuously and only occasionally requires manual input. However, streaming current does not $100 \%$ directly relate to Zeta potential and the desired streaming current set point must be manually evaluated and if plant conditions significantly vary [36].

Moreover, even if the concept of Zeta potential was established more than 100 years ago [37], a limitation on the Zeta potential mean is that it is not a continuous on-line measuring device [36,37]. The streaming current detector was introduced in response to this disadvantage. Its main benefit is rapid detection of plant upsets. In fact, streaming current is another mean to evaluate Zeta potential, but it is really in relation with the Zeta potential of a solid surface, such as the walls of a cylindrical tube, and not the Zeta potential of the colloid. Streaming current is well used as an on-line controller of Zeta potential, but it is only an indication since the value is not scaled. In other words, as shown above, a change in 10 streaming current units does not correspond directly to a Zeta potential change of $10 \mathrm{mV}$. Moreover, the zero position is frequently shifted importantly from true zero. It was proposed that a streaming current monitor must be usually calibrated using a Zeta meter [37]. If cost is not a problem then this will conduct to an extremely accurate handling of the Zeta potential in the coagulated water. Practically, it is much easier and almost as precise to utilize jar tests to calibrate the streaming current monitor. Drinking water utilities frequently utilize streaming current monitors in their plants and utilize Zeta potential meters in their central laboratories [36,38].

Furthermore, there are updated versions of Zeta potential measuring devices (e.g., Malvern Zetasizer ${ }^{\circledR}$ [39]) based on the Doppler velocitometry. In fact, Zeta potential is evaluated by applying an electric field through the dispersion. Colloids within the dispersion with a Zeta potential will migrate toward the electrode of opposite charge with a velocity proportional to the magnitude of the Zeta potential. This velocity is evaluated using the phenomenon of laser Doppler anemometry. The frequency shift, or phase shift, of an incident laser beam produced by these displacing colloids is evaluated in terms of the particle mobility, and this mobility is related to the Zeta potential by inputting the dispersant viscosity, and the application of the Smoluchowski or Huckel theories [39].

\subsection{Finding the Optimal Flocculation Point with a Streaming Potential Instrument}

Researchers such as Wang [40] affirmed that once the optimal operating conditions are established using laboratory tests, the streaming current devise can be called to fix them by controlling the variation of the charge density of the colloids. However, these devices have not been helpful for evaluating the optimal operating conditions since they are not able to find the neutral charge point, which is theoretically the optimal chemical dosage point. As an illustration, if you were to take a bucket of water from the river, you could determine its $\mathrm{pH}$ value. You would then have a starting point for adjusting the $\mathrm{pH}$ to the desired point. The same would be correct for temperature, conductivity, etc. Theoretically, you have to be able to determine the net charge density of the water as well, providing a starting point for adjusting it for optimal coagulation. On the other hand, traditional streaming current devices can only determine the relative change of the charge density in the suspension; they cannot measure the neutral charge point, which is the baseline determination for chemical optimization [40]. However, this is not correct if a titration is realized using the coagulant chemical while determining streaming current. Table 2 shows how the laboratory streaming current monitor is utilized [15].

Table 2. How the laboratory streaming current monitor is used [15].

How the laboratory streaming current monitor is used

1. Using a simple titration procedure, the laboratory streaming current monitor is utilized to correlate "best jar" with a quantified charge value and optimum plant performance. This provides a quick, easy and visible way for operators to understand the relationship between water quality and streaming current.

2. Once this correlation is determined, jar tests usually becomes less frequent or unnecessary. If the plant has an on-line streaming current monitor, the laboratory unit serves as a periodic verification of its operation just like a laboratory $\mathrm{pH}$-meter, or turbidity meter does for on-line instruments.

3. The laboratory streaming current monitor can also be a useful tool for comparing strength/activity of different coagulants/polymers prior to full scale trials.

\subsubsection{Streaming Current Technique}

As shown above, in a streaming current device, water is pushed through by a piston in the cylinder (Fig. 3) [40-42]. The relative motion between the piston and the cylinder walls produces a charged stream, which generates a potential difference (voltage) through the electrodes in the cylinder. The signal is transformed to a streaming potential signal. The streaming current method has to be able to determine the real net charge density in the sample suspension, not only the relative variation of the charge density [40]. This is the same case as in the determination of a voltage with a voltmeter, which determines voltage magnitude as well as its polarity. 
For the same concept, the streaming current device has to be able to evaluate the net charge magnitude and polarity. If the suspension being examined is negatively charged, a streaming current device should show the negative polarity as well as the intensity on a linear scale. The same device has to indicate a positive signal for positively charged suspension. When suspension is electrically neutral (positive and negative charges are exactly equilibrated), the device has to indicate the value of zero [40]. Fig. 4 shows a streaming current device measurement for suspension samples with different charge distributions [40,43].

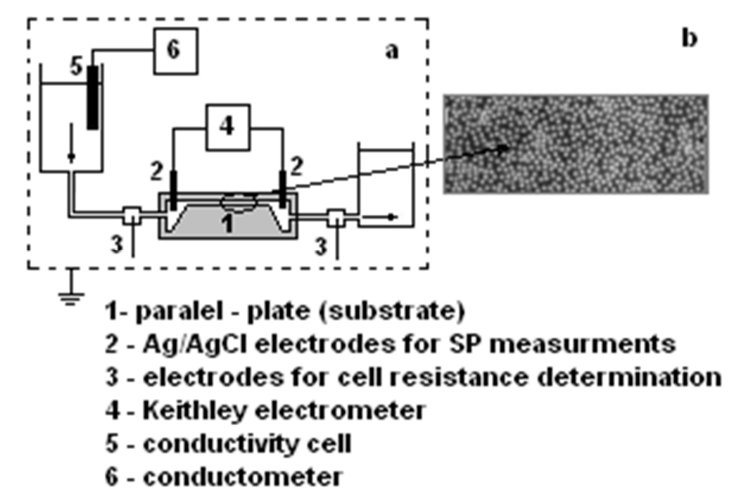

Fig. 3. A schematic view of the parallel-plate channel cell used for streaming potential (SP) measurements of particle covered surfaces, part " $a$ ". In part " $b$ " the micrograph of deposited particles is shown (polystyrene latex particles coverage 0.25 , diameter $800 \mathrm{~nm}$ ) [41].

\section{Negatively Charged Water 0 Positively Charged Water}

\begin{tabular}{|c|c|}
\hline $\begin{array}{l}\text { SC value is negative. The } \\
\text { higher the magnitude, the } \\
\text { higher the density of the } \\
\text { negative charges }\end{array}$ & $\begin{array}{l}\text { SC value is positive. The } \\
\text { higher the magnitude, the } \\
\text { higher the density of the } \\
\text { positive charges }\end{array}$ \\
\hline
\end{tabular}

Fig. 4. Charge distributions versus streaming current (SC) value [40].

\subsubsection{Instrument Should Determine Neutral Charge Point and Change in Charge Density}

Theoretically, a streaming current instrument should be able to determine the neutral charge point as well as the variation in charge density on a linear scale [40]. This gives a basic point for chemical optimization and also gives a baseline for comparing results from different coagulants, water sources, and seasonal variations. Empirical data can be registered and consulted as conditions vary, allowing scientific interpretation of process conditions [40].

Each application is different, since are the requirements for coagulant dosage optimization. Although the electrically neutral point is in theory the optimal point, it is not obligatory the desired operating point for all applications. Traditional streaming current instruments are habitually "zeroed" once a desired operating point has been measured, but they cannot be used to detect the neutral charge point [40].

\subsubsection{New Instrument Provides Two Measurement Signals}

It was developed an online streaming potential instrument, the streaming potential system, which gives two measurement signals: an absolute signal and a relative operating signal [40]. The absolute signal determines the net charge density with charge polarity and magnitude, in which the neutral charge point is always shown as zero. The relative signal is adjustable so that the zero point can be set to the desired operating point [40]. Users can utilize the absolute signal to establish the theoretical operating point. The relative signal is utilized when the desired point is different from the theoretical point [40].

A streaming potential system was monted at Crooked Creek Water Reclamation Facility in Norcross, Ga., in July 1998. This online instrument was utilized to control centrate charge. Fig. 5 shows the strong relationship between the streaming potential system signal and polymer dosage.

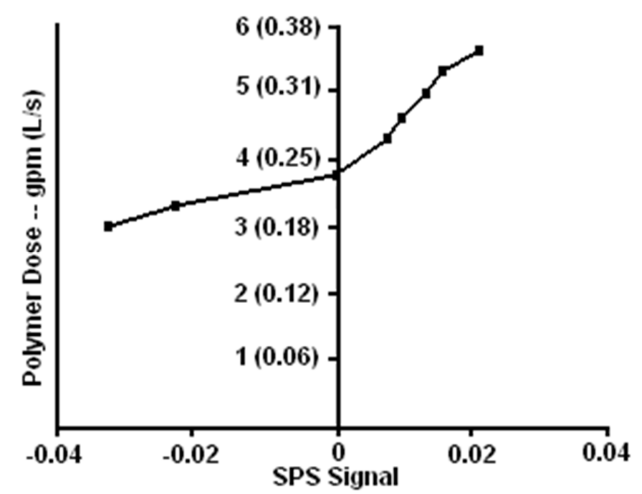

Fig. 5. Relationship between the streaming potential system (SPS) signal and polymer dosage [40].

\subsection{Mechanism of Operation of the Streaming Current Detector}

Barron et al. [5] studied the mechanism of operation of the streaming current detector by the use of well characterized surfaces and dispersed colloidal particles. The response of the instrument in the presence of various electrolytes and with the addition of colloids of known electrokinetic properties shows that the apparatus is measuring a quantity that demonstrates contributions from the charge on both the walls and piston of the apparatus and from colloidal material associated with the surfaces. Analysis of the output of the instrument in terms of the magnitude of the current is poorly taken into consideration by theory. The efficiency of adsorption of colloids, polymers and other simple reagents to the walls and/or piston and the ease of removal of these substrates was shown to be critical to the response of the device [5].

El-Gholabzouri et al. [44] compared the Zeta potential obtained from streaming current and electrophoretic mobility determinations. The electrokinetic experiments were realized using two anionic polystyrene latexes whose surface charge density and average particle diameter were -9.8 and $-3.4 \mu \mathrm{C}$ $\mathrm{cm}^{-2}$ and 0.65 and $1.2 \mu \mathrm{m}$, respectively. For the conversion, two theories were utilized: the Levine et al. theory for the streaming current and O'Brien-White for the electrophoretic mobility measurements. This way most of the phenomena 
taking place at the interface are taken into consideration. The Zeta potentials obtained this manner compare well for the largest latex with the lowest surface charge. However, there are substantial discrepancies for the smaller latex sample with the higher surface charge density. These discrepancies are interpreted in terms of the effect of the surface conductance on the electrokinetic signal [44].

Dentel et al. [45] utilized a streaming current detector in continuous flow experiments to study its response to different conditions. Buffered water and kaolinite systems were coagulated with aluminium sulphate (alum) at various doses. The dose was incremented in a stepwise manner while monitoring streaming current detector output, or alternated between samples with and without alum added. It was established that the streaming current detector responded rapidly and reversibly to variations in sample characteristics over a large interval of coagulant doses. Readings were similar to those realized from batch streaming current detector determinations. However, when extremely high doses of alum or ferric chloride $\left(2 \times 10^{-3} \mathrm{M}\right.$ as $\mathrm{A} 1$ or $\left.\mathrm{Fe}\right)$ were injected, the streaming current detector signal became erratic. Extent and characteristics of this effect differed following the coagulant utilized, delay time between the coagulant addition and streaming current detector sampling, coagulant dose and whether or not an ultrasonic cleaning accessory was used. Several different cleaning methods were shown to alleviate the difficulties, but some cleaning agents themselves interfered with streaming current detector output [45].

Childress and Elimelech [46] utilized a streaming potential analyzer to study the effect of solution chemistry on the surface charge of four commercial reverse osmosis and nanofiltration membranes. Zeta potentials of these membranes were examined for aqueous solutions of various chemical compositions over a $\mathrm{pH}$ interval of 2 to 9 . In the presence of an indifferent electrolyte $(\mathrm{NaC} 1)$, the isoelectric points of these membranes range from 3.0 to 5.2. The curves of Zeta potential versus solution $\mathrm{pH}$ for all membranes show a shape characteristic of amphoteric surfaces with acidic and basic functional groups. Results with salts containing divalent ions $\left(\mathrm{CaCl}_{2}, \mathrm{Na}_{2} \mathrm{SO}_{4}\right.$, and $\left.\mathrm{MgSO}_{4}\right)$ show that divalent cations more readily adsorb to the membrane surface than divalent anions, especially in the higher $\mathrm{pH}$ interval. Three sources of humic acid, Suwannee River humic acid, peat humic acid, and Aldrich humic acid, were utilized to study the effect of dissolved natural organic matter on membrane surface charge. Other solution chemistries implicated in their investigation comprise an anionic surfactant (sodium dodecyl sulfate) and a cationic surfactant (dodecyltrimethylammonium bromide). Results illustrate that humic substances and surfactants readily adsorb to the membrane surface and markedly effect the membrane surface charge [46].

In 1974, Cserfalvi et al. [47] established that because of optical reasons, electrophoretic measuring methods utilized for the measurement of the electrokinetlc potential of dispersed colloids, cannot be applied to macromolecular colloids of low concentration.

Recently, Adamczyk et al. [41] discussed recent developments in the field of streaming current/streaming potential determination for surfaces covered by particles, including polyelectrolytes and proteins. They examined the new theoretical results enabling us measure quantitatively the relationship between the streaming potential and surface coverage of colloids. They discussed and explained experimental results achieved for model systems of monodisperse polymeric particles in terms of the theoretical approach. They also pointed out a major utility of the streaming potential measurements for determination of submonolayer coverages of particles and proteins [41].

\section{Charge Neutralization as the Key Mechanism in Coagulation/Flocculation}

In coagulation process, the importance of charge neutralization mechanism is established in several studies using clay suspensions, organic matters (natural organic matter and dyes) solutions, micro-algae and microorganisms suspensions since the beginning of the coagulation/flocculation investigations. In fact, the net negative charge on colloids in most raw waters and the coagulant dose are typically imposed by the concentration of natural organic matter. For example, dissolved or sorbed humic materials at neutral $\mathrm{pH}$ have $\sim 10 \mathrm{meq}$ of negative charge per $\mathrm{g}$ of natural organic matter. The most highly charged clays have a negative charge as high as 1 meq per $g$ of clay. Thus, for equal concentrations of natural organic matter and total suspended solids, the minimum coagulant demand for the natural organic matter would be at least 10 times the coagulant demand for the total suspended solids [16].

As an illustration, in 1966, Cardwell [48] suggested a technique for studying adsorption in which the detection is realized by a streaming current method. This method makes use of an instrument performing continuous measurements for studying an adsorption process. A study has been accomplished of the adsorption of cetyl dimethyl benzyl ammonium chloride by a monoionic sodium bentonite. The adsorption was followed in two parts: the amount adsorbed to the cationic exchange capacity of the clay and the amount adsorbed from this point to the critical micelle concentration of the quaternary salt [48].

Kam and Gregory [49] studied the anionic charge carried by aquatic humic substances which have a major part in their interaction with metal ions and other cationic species. In fact, removal of such substances by coagulation/flocculation process can be, at least partly, achieved by charge neutralization. They examined the charge densities of a commercial humic acid and an aquatic humic extract by following their interactions with a series of synthetic cationic polyelectrolytes. The methods utilized were colloid titration by spectrophotometry and streaming current detection, and 
flocculation determined by color removal and by an optical monitoring method. For a given cationic polyelectrolyte, all four methods gave charge densities for humic substances which were in good correlation. However, great differences in the apparent humic charge density were detected, depending on the charge density of the cationic polyelectrolyte utilized. With low charge density polyelectrolytes, the apparent anionic charge of the humic substances was detected to be low. With higher polyelectrolyte charge densities, the apparent humic substance charge density augments and arrives to a limiting value when the polyelectrolyte charge is bigger than $\sim 3$ $\mathrm{meq} / \mathrm{g}$. This shows a non-stoichiometric interaction between the anionic sites of the humic substances and the cationic charges of the low-charge polyelectrolytes. Optimum flocculation of humics is produced with less cationic charge in the case of low-charge polyelectrolytes than those with higher charge density. However, the degree of removal was greatly better in the latter case. In all cases, the molecular weight of the cationic polyelectrolytes (over a range from about 50,000 to 15 million) is shown to have no effect on the results [49].

$\mathrm{Wu}$ et al. [50] studied the interactions of silica microspheres by light scattering in presence of alum and polyaluminium chloride $(\mathrm{PACl})$ with various $\mathrm{OH} / \mathrm{Al}$ ratios. They examined coagulation behaviors using different coagulant dosages at constant $\mathrm{pH}(6.5)$ and salt concentration $(0.01 \mathrm{~mol} / \mathrm{L})$. Depending on the measurement of size distribution and Zeta potential, charge neutralization was suggested to be the basic coagulation step for all the coagulants while other distinct coagulation steps were also implicated based on in situ formed or preformed hydrolyzing products. Precipitate coverage and sweep flocculation were called for alum, contrasted to polycation patch and bridge aggregation for $\mathrm{PACl}$ [50].

Recently, $\mathrm{Xu}$ et al. [7] focused on the effect of coagulant dose and $\mathrm{pH}$ on the coagulation behaviors of nano- $\mathrm{Al}_{13}$ polymer $\left(\mathrm{Al}_{13} \mathrm{O}_{4}(\mathrm{OH})_{24}{ }^{7+}\right)$ with respect to the treatment of low specific UV absorbance surface water. The elimination of fine particles and natural organic matter was studied under different coagulation conditions. $\mathrm{PACl}$ and traditional aluminum coagulant, alum, were utilized for purpose of comparison. Floc size, strength and fractal structure were examined under different coagulation conditions. The results demonstrated that fine particles, and hydrophobic natural organic matter with large molecular weight, could be easily eliminated by the three coagulants in a wide dose range (5$17 \mathrm{mg} / \mathrm{L})$. While the proportion of hydrophilic natural organic matter in the removed dissolved organic matter was bigger in $\mathrm{Al}_{\mathrm{m}}$ and $\mathrm{Al}_{13}$ species coagulation at low and moderate dose (lower than $11 \mathrm{mg} / \mathrm{L}$ ). Neutral and alkaline favored the particle elimination, while acidic $\mathrm{pH}$ participated in better hydrophilic natural organic matter elimination. The floc strength study demonstrated that the floc strength constituted by $\mathrm{Al}_{13}$ under different coagulation conditions was in the following order: $\mathrm{pH} 6.5(15 \mathrm{mg} / \mathrm{L})>\mathrm{pH} 4.0(9$ $\mathrm{mg} / \mathrm{L})>\mathrm{pH} 8.0(15 \mathrm{mg} / \mathrm{L})$. For $\mathrm{Al}_{2}(\mathrm{SO} 4)_{3}$ coagulation, the order was as following: $\mathrm{pH} 4.0(9 \mathrm{mg} / \mathrm{L})>\mathrm{pH} 6.5(15 \mathrm{mg} / \mathrm{L})>$ pH $8.0(15 \mathrm{mg} / \mathrm{L})$. Moreover, the fractal dimension of flocs indicated that $\mathrm{Al}_{13}$ species conducted to compact aggregates at low concentration and $\mathrm{pH}[7]$.

An interesting study was performed by Ye et al. [51], they studied the coagulation behavior of $\mathrm{PACl}$ with various basicities ( $B=\mathrm{OH} / \mathrm{Al}$ values) under different alkalinities. They get better insights into the coagulation mechanisms implicating interactions between hydrolyzed $\mathrm{Al}(\mathrm{III})$ products and colloids. Jar tests were utilized to measure the coagulation efficiencies, including Zeta potentials, residual turbidities and $\mathrm{pH}$ values. An optical control technique of photometric dispersion analyzer was used to follow the coagulation dynamics. The experimental results illustrate that the traditional coagulant such as alum implicates a rapid hydrolysis after dosing and the in situ formed hydrolysis products can destabilize the kaolin particles by precipitation charge neutralization. The preformed polymeric species in PACls show a relatively high stability after dosing and can constitute "electrostatic patches" on clay particle surfaces. These patches play an important role in "electrostatic patch coagulation". Increasing alkalinity increases both precipitation charge neutralization and electrostatic patch coagulation areas. When alkalinity is low alkalinity, electrostatic patch coagulation with high $\mathrm{Al}_{\mathrm{b}}$ contained in PACls works better than precipitation charge neutralization coagulation; increased alkalinity ameliorates the efficiency of traditional coagulant due to sweep flocculation. When alkalinity is higher, more coagulant is required to realize complete charge neutralization. The stoichiometric relationships between the dosage and alkalinity are different following the $B$ values of PACls [51].

\section{Indecisiveness of Electrophoretic Mobility Determination and Effects of Low Temperature on Coagulation}

It is well established that the magnitude of electrophoretic mobility is frequently utilized to represent the repulsion force between colloids in an aqueous system. A generally accepted idea is that colloids will coagulate efficiently when the suspension electrophoretic mobility is near to zero, which is frequently achieved by dosing trivalent cations such as Fe(III) [52,53]. Concerning Fe(III) coagulation, however, Xiao et al. [53] found that colloids were firstly enmeshed by voluminous ferric hydroxide precipitate or flocs, and the enmeshment of colloids by flocs was not dependent of the suspension electrophoretic mobility during $\mathrm{Fe}(\mathrm{III})$ coagulation. A suspension with either highly negative or positive electrophoretic mobility could be well coagulated and clarified if the solution $\mathrm{pH}$ and $\mathrm{Fe}$ (III) concentration favored the formation and fast growth of ferric hydroxide precipitate. For an efficient Fe(III) coagulation, the electrophoretic mobility was not obligatory zero [52].

In addition, Xiao et al. [54] compared coagulation of kaolinite suspensions at low temperatures with that at an 
ambient temperature of $22^{\circ} \mathrm{C}$, and the process was studied with regard to the coagulation rate and chemical characteristics of coagulation. Experiments utilizing a photometric dispersion analyzer proved that coagulation of kaolinite suspensions could be considered as a two-phase process: low temperature importantly decreases the coagulation rate of the first phase but not that of the second one. On the other hand, results illustrated that low temperature did not serve to impede the hydrolysis of aluminum [Al(III)] within $1 \mathrm{~min}$ of alum addition. The measurements of electrophoretic mobility show that destabilization of kaolinite particles by hydrolyzed Al species was not decreased by low temperature within 1 min of alum addition. Slow coagulation at low temperature is attributed to the lowered coagulation rate but not the altered chemistry aspect of $\mathrm{Al}(\mathrm{III})$. Moreover, the change in settled turbidity after 20-min flocculation as a function of coagulant dosage was more significant in the cold due to the low coagulation rate.

Consequently, Xiao et al. [52,54] confirmed that Zeta potential (or electrophoretic mobility) is not an important determinant when a sweep coagulation mechanism dominates.

\section{Practical Considerations}

As concluded by Dempsey [16], plant operators should take into consideration the coagulation mechanism at their facility and the diagnostic tools that can be utilized to ameliorate treatment efficiency or to respond to variations in water quality. As an example, the city of Milwaukee WI changed from alum to PAC1 during the winter of '1992-93. This conducted to a decrease in coagulant dose from $\sim 30$ ppm alum to $\sim 5 \mathrm{ppm}$ PAC1. It is possible the destabilization mechanism was varied from sweep flocculation to charge neutralization but jar tests (rather than electrokinetic tests) were retained for determination of convenient coagulation conditions. Spring '1993 brought unusual weather conditions, culminating with a significant freeze between two thaws. These conditions are frequently related to rapidly deteriorating water quality due to run-off, sieving of contaminants behind a slush dam followed by release during a thaw, and the effects of cold water on the position of the $\mathrm{Al}(\mathrm{OH})_{3(\mathrm{am})}$ solubility diagram. Moreover, Milwaukee suffered some critical equipment and chemical failures. Hundreds of thousands were sickened by cryptosporidiosis [16]. It is not possible to tell today whether the system failed in part because of overdosing or underdosing. It is likely that the problems could have been easily analyzed and treated if Zeta meters or streaming current monitors had been utilized [16].

Furthermore, Dempsey [16] presented a strategy for application of Zeta meters for control of charge neutralization. Finally, coagulant control in water treatment [55-62] remains difficult to be well modeled and more progress is needed in coagulation process comprehension and quantification.

\section{Conclusions}

This review discusses the common approaches of measuring electrokinetic properties of colloidal systemsmainly Zeta potential, streaming potential, and streaming current - with respect to optimization of coagulation/flocculation processes in water treatment. From this review, three main conclusions are drawn:

1. The electric double layer plays the major determinant role of colloidal interactions and colloid stability. The charge and potential of a range of surfaces and colloidal particles have been measured successfully in order to quantify the electric double layer for various systems. Surface charge may be determined by charge titration, whereas Zeta potential is generally determined by electrokinetic techniques (e.g., electrophoresis, streaming potential, electroosmosis). The distinction between the surface potential and the Zeta potential is that the latter applies at the plane of shear, which may be up to 2-3 water diameters away from the surface.

2. From a user's point of view, streaming current assures a good on-line tool for optimizing and controlling coagulant dose. With the development of laboratory streaming current monitors, users can verify on-line operation and evaluate coagulant dose quicker than performing jar tests, which remain important. The combination of on-line and laboratory units help to characterize the best coagulation for a varying water source.

3. Zeta potential or electrophoretic mobility is not an important factor when sweep coagulation dominates, which is the common case in the real-world coagulation processes.

\section{Acknowledgements}

The present research work was undertaken by the Binladin Research Chair on Quality and Productivity Improvement in the Construction Industry funded by the Saudi Binladin Constructions Group; this is gratefully acknowledged. The opinions and conclusions presented in this paper are those of the authors and do not necessarily reflect the views of the sponsoring organization.

\section{References}

[1] D. Ghernaout and M.W. Naceur, Ferrate(VI): In situ generation and water treatment - A review, Desalin. Water Treat., 30 (2011) 319-332.

[2] B. Ghernaout, D. Ghernaout and A. Saiba, Algae and cyanotoxins removal by coagulation/flocculation: A review, Desalin. Water Treat., 20 (2010) 133-143.

[3] W. Yu, J. Gregory and L.C. Campos, Breakage and re-growth of flocs formed by charge neutralization using alum and polyDADMAC, Water Res., 44 (2010) 3959-3965.

[4] R.J. François, Strength of aluminium hydroxide flocs, Water Res., 21 (1987) 1023-1030. 
[5] W. Barron, B.S. Murray, P.J. Scales, T.W. Healy, D.R. Dixon and M. Pascoe, The streaming current detector: a comparison with conventional electrokinetic techniques, Colloids Surf. A: Physicochem. Eng. Aspects, 88 (1994) 129-139.

[6] S.R. Gray and C.B. Ritchie, Effect of organic polyelectrolyte characteristics on floc strength, Colloids Surf. A: Physicochem. Eng. Aspects, 273 (2006) 184-188.

[7] W. Xu, B. Gao, Y. Wang, Z. Yang and X. Bo, Role of $\mathrm{Al}_{13}$ species in removal of natural organic matter from low specific UV absorbance surface water and the aggregates characterization, Chem. Eng. J., 171 (2011) 926- 934.

[8] C. Huang and H. Shiu, Interactions between alum and organics in coagulation, Colloids Surf. A: Physicochem. Eng. Aspects, 113 (1996) 155-163.

[9] J. Oh and S. Lee, Influence of streaming potential on flux decline of microfiltration with in-line rapid pre-coagulation process for drinking water production, J. Membr. Sci., 254 (2005) 39-47.

[10] H. Liu, C. Hu, H. Zhao and J. Qu, Coagulation of humic acid by $\mathrm{PACl}$ with high content of $\mathrm{Al}_{13}$ : The role of aluminum speciation, Sep. Purif. Technol., 70 (2009) 225-230.

[11] S. Byun, J. Oh, B.-Y. Lee and S. Lee, Improvement of coagulation efficiency using instantaneous flash mixer (IFM) for water treatment, Colloids Surf. A: Physicochem. Eng. Aspects, 268 (2005) 104-110.

[12] W.F. Gerdes, A new instrument -- The streaming current detector, Paper presented at the $12^{\text {th }}$ National ISA Analysis Instrument Symposium, pp. 181-198, Houston, Texas, May 11-13, 1966.

[13] (a) S. Xia, X. Li, Q. Zhang, B. Xu and G. Li, Ultrafiltration of surface water with coagulation pretreatment by streaming current control, Desalination, 204 (2007) 351-358.

(b) H.N. Jang, D.S. Lee and S.O. Ko, The effects of coagulation with MF/UF membrane filtration in drinking water treatment, Desalin. Water Treat., 19 (2010) 138-145.

[14] S.K. Dentel, A.V. Thomas and K.M. Kingery, Evaluation of the streaming current detector--I. Use in jar tests, Water Res., 23 (1989) 413-421.

[15] Laboratory streaming current monitor defines best coagulation chemistry,

http://www.chemtrac.com/products/cca3100/documents/Labor atory_SCM.pdf (accessed on 29/06/11).

[16] B.A. Dempsey, Coagulant characteristics and reactions (Ch. 2), In: G. Newcombe and D. Dixon (Eds.), Interface science in drinking water treatment, Elsevier, 2006.

(a) W.E. Neuman, Optimizing coagulation with pilot filters and zeta potential, J. Am. Water Works Ass. 73 (1981) 472475 .

(b) A.V. Delgado, F. González-Caballero, R.J. Hunter, L.K. Koopal and J. Lyklema, Measurement and interpretation of electrokinetic phenomena, J. Colloid Interface Sci., 309 (2007) 194-224.

[17] (a) E.L. Bean, S.J. Campbell, F.R. Anspach, R.W. Ockershausen, C.J. Peterman, Zeta potential measurements in the control of coagulation chemical doses, J. Am. Water Works Ass. 56 (1964) 214-227. (b) M. Elimelech, W.H. Chen and J.J. Waypa, Measuring the zeta (electrokinetic) potential of reverse osmosis membranes by a streaming potential analyzer, Desalination, 95 (1994) 269-266.

[18] D. Ghernaout, B. Ghernaout and M.W. Naceur, Embodying the chemical water treatment in the green chemistry-A review, Desalination, 271 (2011) 1-10.

[19] R. Wäsche, M. Naito and V.A. Hackley, Experimental study on zeta potential and streaming potential of advanced ceramic powders, Powder Technol., 123 (2002) 275-281.

[20] P.R. Johnson, A comparison of streaming and microelectrophoresis methods for obtaining the $\zeta$ potential of granular porous media surfaces, J. Colloid Interface Sci., 209 (1999)264-267.

[21] S. Wall, The history of electrokinetic phenomena, Current Opinion Colloid Interface Sci., 15 (2010) 119-124.

[22] (a) D. Edney, Introduction to the theory of the streaming current http://www.accufloc.com/downloads/SCMTheory.pdf (accessed on 29/06/11).

(b) W. Olthuis, B. Schippers, J. Eijkel and A. van den Berg, Energy from streaming current and potential, Sensors Actuators B, 111-112 (2005) 385-389.

[23] (a) G. Lagaly, Colloid clay science (Ch. 5), In: F. Bergaya, B.K.G. Theng and G. Lagaly (Eds.), Handbook of clay science, Developments in clay science (Vol. 1), Elsevier, 2006.

(b) T. Ishibashi, Coagulation mechanisms: An electron microscopic study using aluminum sulfate, J. Am. Water Works Ass. 72 (1980) 514-518.

[24] D. Ghernaout, B. Ghernaout and A. Kellil, Natural organic matter removal and enhanced coagulation as a link between coagulation and electrocoagulation, Desalin. Water Treat., 2 (2009) 203-222.

[25] J. Zhang and J. Buffle, Kinetics of hematite aggregation by polyacrylic acid: Importance of charge neutralisation, J. Colloid Interface Sci., 174 (1995) 500-509.

[26] M. Zembala, Electrokinetics of heterogeneous interfaces, Adv. Colloid Interface Sci., 112 (2004) 59- 92.

[27] F. Mietta, C. Chassagne and J.C. Winterwerp, Shear-induced flocculation of a suspension of kaolinite as function of $\mathrm{pH}$ and salt concentration, J. Colloid Interface Sci., 336 (2009) 134 141.

[28] M.A. Yukselen and J. Gregory, The reversibility of floc breakage, Int. J. Miner.Process., 73 (2004) 251-259.

[29] I.G. Droppo, K. Exall and K. Stafford, Effects of chemical amendments on aquatic floc structure, settling and strength, Water Res., 42 (2008) 169-179.

[30] K. Sadlej, Streaming potential and streaming current of a particle covered surface, Part 2: Virial expansion and simulations, http://fluid.ippt.gov.pl/seminar/text/sadlej280109.pdf, 28/01/09 (accessed on 29/06/11).

[31] Streaming current, http://en.wikipedia.org/wiki/Streaming current (accessed on 28/06/11). 
[32] Encyclopedia2, current,http://encyclopedia2.thefreedictionary.com/Streaming + current\%2Fpotential (accessed on 28/06/11).

[33] M.-S. Chun, S.-Y.Lee, and S.-M. Yang, Estimation of zeta potential by electrokinetic analysis of ionic fluid flows through a divergent microchannel, J. Colloid Interface Sci., 266 (2003) 120-126.

[34] (a) Dispersion technology, Inc.,Streaming Current isochoric and non-isochoric. Seismoelectric effect, http://www.dispersion.com/streaming-current.html (accessed on $29 / 06 / 11$ ).

(b) A.S. Dukhin, V.N. Shilov, The seismoelectric effect: A nonisochoric streaming current 2 . Theory and its experimental verification, J. Colloid Interface Sci., 346 (2010) 248-253.

[35] C.A. Walker, J.T. Kirby and S.K. Dentel, The streaming current detector: A quantitative model, J. Colloid Interface Sci.,182 (1996) 71-81.

[36] Accufloc, Should I use a zeta potential meter or a streaming current meter? http://www.accufloc.com/zeta_sc.html (accessed on 28/06/11).

[37] Zeta-meter,Everything you want to know about Zeta Potential, http://www.zeta-meter.com/everything.pdf (accessed on 28/06/11).

[38] C. Igarashi and K. Nishizawa, Effect of turbulent flow condition on streaming potential measurement using cylindrical cells, Colloids Surf. A: Physicochem. Eng. Aspects, 303 (2007) 235-240.

[39] (a) M.J. Jaycock, Assumptions made in the measurement of zeta-potential by streaming current/potential detectors, Paper Technol., 36 (1995) 35-38.

(b) Malvern Zetasizer ${ }^{\circledR}$,Zeta potential measurement using laser Doppler electrophoresis (LDE), http://www.malvern.com/LabEng/technology/zeta_potential/z eta_potential_LDE.htm (accessed on 20/12/11).

(c) L. Li, H. Zhang, G. Pan, Influence of zeta potential on the flocculation of cyanobacteria cells using chitosan modified soil, J. Environ. Sci. 28 (2015) 47-53.

[40] J. Wang, Finding the optimal flocculation point with a streaming potential instrument, J. Am. Water Works Assoc., November (2001) 54-56, http://www.sentrolsystems.com/AWWA_paper.pdf (accessed on $28 / 06 / 11$ ).

[41] Z. Adamczyk, M. Nattich and M. Zaucha, Electrokinetics of particle covered surfaces, Current Opinion Colloid Interface Sci., 15 (2010) 175-183.

[42] K. Sadlej, Streaming potential and streaming current of a particle covered surface, Part 1, http://fluid.ippt.gov.pl/seminar/text/sadlej210109.pdf, 21/01/09 (accessed on 29/06/11).

[43] T.J. Day, On-line control of coagulants, polymer dosing with streaming current technology, http://www.waterworld.com/index/display/articledisplay/200746/articles/waterworld/volume-20/issue3/editorial-focus/on-line-control-of-coagulants-polymerdosing-with-streaming-current-technology.html, $21 / 06 / 11$ (accessed on 28/06/11).
[44] O. El-Gholabzouri, M.A. Cabrerizo and R. Hidalgo-Àlvarez, Comparative electrophoretic mobility and streaming current study for $\zeta$-potential determination, Colloids Surf. A: Physicochem. Eng. Aspects, 159 (1999) 449-457.

[45] S.K. Dentel, A.V. Thomas and K.M. Kingery, Evaluation of the streaming current detector--II. Continuous flow tests, Water Res., 23 (1989) 423-430.

[46] A.E. Childress and M. Elimelech, Effect of solution chemistry on the surface charge of polymeric reverse osmosis and nanofiltration membranes,J. Membr. Sci., 119 (1996) 253-268.

[47] T. Cserfalvi, T. Meisel and E. Pungor, Determination of the electrokinetic potential of dispersion and macromolecular colloids by measurement of the streaming potential. I., Electroanalytical Chem. InterfactalElectrochem., 53 (1974) 365-370.

[48] P.H. Cardwell, Adsorption studies using a streaming current detector, J. Colloid Interface Sci., 22 (1966) 430-437.

[49] (a) S.-K. Kam and J. Gregory, The interaction of humic substances with cationic polyelectrolytes, Water Res., 35 (2001) 3557-3566.

(b) L.H. Mikkelsen, Applications and limitations of the colloid titration method for measuring activated sludge surface charges, Water Res., 37 (2003) 2458-2466.

(c) S. Bratskaya, A. Golikov, T. Lutsenko, O. Nesterova and V. Dudarchik, Charge characteristics of humic and fulvic acids: Comparative analysis by colloid titration and potentiometric titration with continuous $\mathrm{p} K$-distribution function model, Chemosphere, 73 (2008) 557-563.

[50] X. Wu, X. Ge, D. Wang and H. Tang, Distinct mechanisms of particle aggregation induced by alum and $\mathrm{PACl}$ : Floc structure and DLVO evaluation, Colloids Surf. A: Physicochem. Eng. Aspects, 347 (2009) 56-63.

[51] (a) C. Ye, D. Wang, B. Shi, J. Yu, J. Qu, M. Edwards and H. Tang, Alkalinity effect of coagulation with polyaluminum chlorides: Role of electrostatic patch, Colloids Surf. A: Physicochem. Eng. Aspects, 294 (2007) 163-173.

(b) Y.-L. Cheng, R.-J. Wong, J.C.-T. Lin, C. Huang, D.-J. Lee, A.S. Mujumdar, Water coagulation using electrostatic patch coagulation (EPC) mechanism, Drying Technol. 28 (2010) 850-857.

[52] F. Xiao, X. Zhang and C. Lee, Is electrophoretic mobility determination meaningful for aluminum(III)coagulation of kaolinite suspension?, J. Colloid Interface Sci., 327 (2008) 348-353.

[53] F. Xiao, X. Zhang and J. Ma, Indecisiveness of electrophoretic mobility determination in evaluating $\mathrm{Fe}(\mathrm{III})$ coagulation performance, Sep. Purif. Technol., 68 (2009) 273-278.

[54] F. Xiao, J. Ma, P. Yi and J.-C.H. Huang, Effects of low temperature on coagulation of kaolinite suspensions, Water Res., 42 (2008) 2983-2992.

[55] S.K. Dentel, Coagulant control in water treatment, Crit. Rev. Environ. Control, 21(1991) 41-135.

[56] O. Oriekhova, S. Stoll, Investigation of $\mathrm{FeCl} 3$ induced coagulation processes using electrophoretic measurement, nanoparticle tracking analysis and dynamic light scattering: Importance of $\mathrm{pH}$ and colloid surface charge, Colloid Surface A 461 (2014) 212-219. 
[57] E.A. López-Maldonado, M.T. Oropeza-Guzman, J.L. JuradoBaizaval,A. Ochoa-Terán, Coagulation-flocculation mechanisms in wastewater treatment plants through zeta potential measurements, J. Hazard. Mater., 279 (2014) 1-10.

[58] D. Ghernaout, S. Moulay, N. Ait Messaoudene, M. Aichouni, M.W. Naceur, A. Boucherit, Coagulation and chlorination of NOM and algae in water treatment: A review, Intern. J. Environ. Monitor. Analysis, 2 (2014) 23-34.

[59] D. Ghernaout, The hydrophilic/hydrophobic ratio vs. dissolved organics removal by coagulation - A review, J. King Saud University - Sci., 26 (2014) 169-180.
[60] D. Ghernaout, The best available technology of water/wastewater treatment and seawater desalination: Simulation of the open sky seawater distillation, Green Sustain. Chem., 3 (2013) 68-88.

[61] D. Ghernaout, B. Ghernaout, Sweep flocculation as a second form of charge neutralisation - a review, Desalin. Water Treat. 44 (2012) 15-28.

[62] J. Duan, J. Wang, T. Guo, J. Gregory, Zeta potentials and sizes of aluminum salt precipitates - Effect of anions and organics and implications for coagulation mechanisms, J. Water Process Eng. 4 (2014) 224-232. 